\title{
Prevalence of the hepatitis B surface antigen in a population of workers in Cameroon ${ }^{*}$
}

\author{
Firmin Ankouane Andoulo ${ }^{1}$, Michèle Tagni-Sartre ${ }^{2}$, Dominique Noah Noah ${ }^{3 \#}$, Roger Djapa ${ }^{1}$, \\ Elie Claude Ndjitoyap Ndam ${ }^{3}$

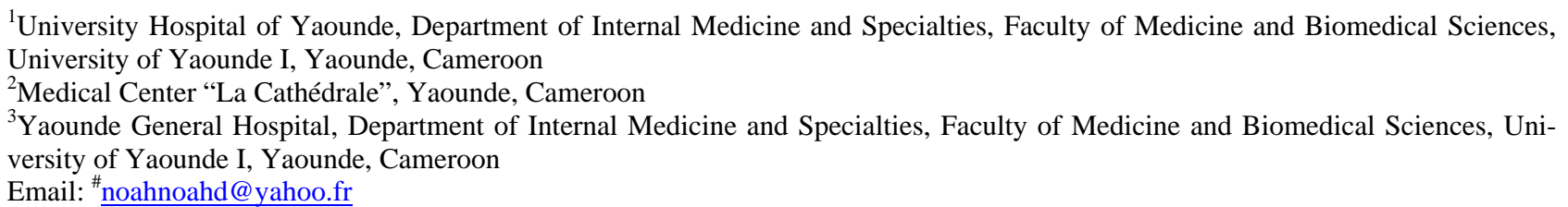

Received 30 September 2013; revised 29 October 2013; accepted 15 November 2013

Copyright (C) 2013 Firmin Ankouane Andoulo et al. This is an open access article distributed under the Creative Commons Attribution License, which permits unrestricted use, distribution, and reproduction in any medium, provided the original work is properly cited. In accordance of the Creative Commons Attribution License all Copyrights (C) 2013 are reserved for SCIRP and the owner of the intellectual property Firmin Ankouane Andoulo et al. All Copyright (C) 2013 are guarded by law and by SCIRP as a guardian.

\begin{abstract}
Hepatitis B surface antigen prevalence in populations of blood donors in Cameroon is estimated at 6\% $16 \%$. As such, the Objective of this study was to determine the prevalence of Hepatitis $B$ surface antigen in a population of bank employees, who represent a sample closer to the general population. In tests carried out both Yaounde and Douala in December 2011, we detected the hepatitis $B$ surface antigen among 267 workers, including 151 men and 116 women of a median age of 37 years. The Results obtained revealed that the overall prevalence stood at $7.1 \%$, with a $9.9 \%$ prevalence ratio in men, three times higher than that in women $(3.4 \%)$. Subjects aged 20 - 29 years and senior staffs were more affected (each of them recording $8.1 \%$ ). Potential nosocomial risks were detected mostly at the level of dental care (52.8\%). Among the other risks of exposure, scarification $(53.6 \%)$ was more frequent. A univariate analysis revealed an insignificant relationship with tattoos (OR 2.6, 95\% CI $0.5-10.8, \mathrm{p}=0.2$ ). These results led to the Conclusion that Hepatitis B surface antigen carrier prevalence in a population of workers in Cameroon is not different from that of blood donors. It is mainly due to early vertical and horizontal contamination.
\end{abstract}

Keywords: Hepatitis B Virus; HBs Antigen; Chronic

*Conflicts of interest: none.

"Corresponding author.
Carrier; Prevalence; Cameroon

\section{INTRODUCTION}

The hepatitis B virus (HBV) can cause liver infection, cirrhosis, liver cancer, liver failure and death [1,2]. According to the World Health Organization (WHO), approximately two billion people have been infected by HBV worldwide [3]. More than 350 million of these people are chronic carriers and can transmit the virus for years, and nearly $25 \%$ of these chronic carriers develop liver diseases such as chronic hepatitis, cirrhosis and hepatocellular carcinoma (HCC) [4]. It is estimated that over 600,000 people die yearly of HBV infection-related complications, particularly in Sub-Saharan Africa and Pacific Asia [3,5]. In developing countries, the effective management of HBV infection is a public health concern. This is due, partly, to the lack of reliable data on the prevalence of infections in the general population [6]. Existing data in Cameroon report prevalence between 6 and $16 \%$ in the population of blood donors in public hospitals [7,8]. Blood donors in Africa, in general, and in Cameroon, in particular, are mostly unemployed and underprivileged youth from poor socio-economic backgrounds which are often exposed to sexually transmitted infections [9]. As concerns public health, data on the prevalence of HBV infection in this population of blood donors should be validated for use within the framework of the Expanded Program on Immunization for children (EPI), including the hepatitis B vaccine, developed in our country on the recommendation of WHO since 2005 [3].

The aim of our study was to estimate HB antigen 
(HBsAg) carrier prevalence in a population of workers and to analyze the determinants associated with HBV infection in our context.

\section{MATERIALS AND METHODS}

We conducted a cross-sectional study in a population of adult workers in Cameroon, specifically in Yaounde and Douala, during voluntary screening within the context of occupational medicine in December 2011. Yaounde and Douala were selected because they are cosmopolitan cities.

The variables recorded were: age, sex, social class (worker, employee, and senior staff), personal and family history, as well as the hepatitis B infection risk factors available from books.

The tests were performed on workers whose hepatitis B-infection status was not known, after filling out a questionnaire on demographic data, risk factors, risk behaviors and health history. Workers were recruited through the medical work and none had objected to the publication of results. Workers who did not give their consent as well as absentees and known hepatitis B carriers were excluded.

The screening tests were performed on a sample of 4 milliliters of venous blood taken at the elbow groove. The serum collected was sent to two different laboratories in each city, which is four laboratories in total, so that the results could be compared. The search for HBsAg was performed done using a 3rd generation ELISA test, a commercial kit (DIA-HBV ${ }^{\circledR}$, DiaProph. Med, Ukraine, Russia). The results would be positive if the optical density (OD) of the test sample was greater than the threshold OD. The test would be negative if the threshold OD was greater than the OD test sample. Laboratory results which did not tally were excluded in view of the final analysis.

The data was entered and analyzed using the French version of the Epi Info 6.04 software and Excel 2007. As concerns the quantitative variables, the median and interquartile (IQR) were calculated. The proportions were established for the qualitative variables with their confidence intervals (CI) at 95\%.

To examine the relationship between two discrete variables, we used the Pearson $\chi^{2}$ test with Yates' modification and Fisher's exact test for reduced populations, an accepted significance level of $5 \%$.

\section{RESULTS}

\subsection{Study Population and HBsAg Carrier Prevalence}

The testing involved 288 workers. Ten workers were absent, 05 refused to participate in the screening, 01 was hepatitis B positive and was under antiviral treatment. Two hundred and seventy-two workers (94.4\%) were screened for HBsAg. Five results were excluded for the following reasons: Conflicting results $(\mathrm{n}=3)$, No results $(n=1)$, insufficient serum $(n=1)$. Two hundred and sixty-seven (92.7\%) workers were retained of which 49 $(18.4 \%)$ in Douala and 218 (81.6\%) in Yaounde. Subjects aged 30 - 39 years made up the majority (44.9\%). There were 151 men (56.6\%) and 116 women (43.4\%) giving a sex ratio of 1.3. Among them, there were 60 senior staff (22.4\%), 104 employees (39\%) and 103 workers (38.6\%). The median age was 37 years (IQR [32 years, 44 years]). The overall prevalence was $7.1 \%(19 / 267)$, with six $(12.2 \%)$ cases in Douala and $13(6 \%)$ cases in Yaounde. Four women $(3.4 \%)$ and 15 men $(9.9 \%)(p=0.004)$ were tested positive. The prevalence was significant in subjects aged $20-29$ years with $8.1 \%(3 / 37)(p=0.02)$. Among social classes, the highest prevalence rate was recorded in senior staff with $8.1 \%(5 / 60)(p=0.2)$ (Table 1).

\subsection{HBV Infection Risk Factors}

Many risk factors were identified. They are shown in Table 2.

In terms of potential nosocomial risk, the main exposure was at the level of dental care, reported 141 times (52.8\%). Among other exposure factors, we observed that scarification was reported 143 times (53.6\%).

Table 1. Demographics and HBsAg prevalence amongst 267 workers.

\begin{tabular}{ccccc}
\hline & $\mathrm{n}$ & (\%) & HBsAg positive n (\%) & $95 \%$ CI \\
\hline $\begin{array}{c}\text { Age, years } \\
\text { (median/IQR) } \\
\text { Gender: }\end{array}$ & & \multicolumn{5}{c}{$37(31.44)$} & \\
Men & 151 & 56.6 & $15(9.9)$ & 7.1 to 23.1 \\
Women & 116 & 43.4 & $4(3.4)$ & 2.8 to 7.1 \\
Age group, years & & & & \\
20 - 29 & 37 & 13.9 & $3(8.1)$ & 7 to 16.9 \\
30 - 39 & 120 & 44.9 & $9(7.5)$ & 2.8 to 12.3 \\
40 - 49 & 82 & 30.7 & $5(6.1)$ & 2.9 to 11.3 \\
50 and + & 28 & 10.5 & $2(7.1)$ & 2.4 to 16.7 \\
Social class & & & & \\
Senior staff & 60 & 22.4 & $5(8.3)$ & 1.3 to 15.3 \\
Employees & 104 & 39 & $8(7.7)$ & 2.6 to 12.8 \\
Workers & 103 & 38.6 & $6(5.8)$ & 1.3 to 10.4 \\
\hline
\end{tabular}

$\mathrm{n}=$ number, $\%=$ percentage, ${ }^{\mathrm{a}} \mathrm{IQR}$ interquartile range, $95 \%$ confidence interval 96\%. 
Table 2. Risk factors for HBV infection.

\begin{tabular}{ccc}
\hline Risk Factors & No. of cases & $\%$ \\
\hline Maternal history & 6 & 2.2 \\
Personal history of jaundice & 26 & 9.7 \\
Scarification & 143. & 53.6 \\
Tattoo & 20 & 7.5 \\
Piercing & 103 & 38.6 \\
Surgery & 65 & 24.3 \\
Dental care & 141 & 52.8 \\
Gastrointestinal endoscopy & 28 & 10 \\
Blood transfusion or related & 32 & 12 \\
\hline
\end{tabular}

All workers acknowledged that they were heterosexual (100\%) and none admitted using intravenous drugs.

Concerning sexuality, 70 questionnaires were filled out. Of these responses, $40 \%$ reported a number of partners greater than or equal to five, mostly in singles and senior staff. Only six cases (2.2\%) of a history of maternal liver diseases were reported. All workers had at least one known risk factor, and some subjects had several risk factors.

\subsection{The Relative Risk of HBV Infection}

Table 3 shows the known HBsAg risk factors. Male subjects were significantly associated with HBsAg carriage (OR 3.09, 95\% CI 2 - 11.5, p = 0.04). A relationship was found between the other factors, maternal medical history (OR 2.7, 95\% CI: 0.33 to 22.3) and tattoos (OR 2.6, 95\% CI: 0.52 - 10.80).

\section{DISCUSSION}

We believe this study is the first conducted on HBsAg carrier prevalence in the general population in Cameroon. Previous prevalence studies have been conducted on populations which only imperfectly reflect the general population. It is true that it excludes the youth below 20, who (according to the last population census in 2010), represent more than $43.6 \%$ of the country's 20 million inhabitants [10], due to the working age and the majority set at 21 years. However, the study seems to come closer to the general population because its subjects were not selected on the basis of known risk factors, but presumebly healthy subjects.

A prevalence of $7.1 \%$ was found in this range. These lower figures, as compared to WHO estimate of $8 \%$ $20 \%$ which makes Cameroon a highly endemic area, can be explained partly by the exclusion of sexually active people below 20 years, whose vertical and horizontal
Table 3. Relative risk of HBsAg carrier (univariate analysis).

\begin{tabular}{cccc}
\hline Risk Factors & OR & (95\%) & p \\
\hline Female & 1 & - & - \\
Male & 3.09 & $(2$ to 11.50$)$ & 0.04 \\
Maternal history & 2.70 & $(0.3$ to 22.30$)$ & 0.5 \\
Scarification & 0.96 & $(0.3$ to 2.70$)$ & 0.9 \\
Tattoo & 2.6 & $(0.5$ to 10.80$)$ & 0.2 \\
Piercing & 0.55 & $(0.2$ to 1.71$)$ & 0.25 \\
Gastrointestinal endoscopy & 1 & $(0.0$ to 4.99$)$ & 0.6 \\
Blood transfusion & 0.39 & $(0.1$ to 2.97$)$ & 0.3 \\
Surgery & 0.56 & $(0.1$ to 2.17$)$ & 0.27 \\
Dental care & 0.79 & $(0.3$ to 2.21$)$ & 0.6 \\
\hline
\end{tabular}

OR odds ratio, CI confidence interval, $\mathrm{p} p$-value.

modes of contamination are well documented [11,12], but also due to the selection of underprivileged individuals presumably less exposed to sexually transmitted infections and certain customary rites [13,14]. Previous studies in our country and in some sub-Saharan African countries of the same endemic area revealed higher prevalence in the 20 - 29 years age group and among socioeconomically underprivileged patients $[7,8,11,12,15]$. The exclusion people below 20 years could have been a selection bias, if there was known high prevalence in that age group. In this range, we would have expected to find a lower prevalence among workers, if one were to consider that some companies restrict access to employment where HBsAg are detected in a pre-recruitment medical examination. This result can be explained by the fact that recruitment reports are not systematic. Only one worker knew their HIV status. Most refused to undergo testing because they feared the results, on the one hand, and the possibility of being screened for HIV without their consent, on the other hand. However, if the prerecruitment examination were effective, it would have meant that the contamination factors in this range are the same as those known among Western workers, that is nosocomial exposure and drug addiction [13], or those associated in sub-Saharan Africa to poor hygiene conditions existing especially during treatment, often neglected during examination [12], and finally, contamination during sexual intercourse. It is important to compare this with a survey conducted in France in 2003-2004 with a population of 18 - 80 years [13]. The said study brings out the differences in prevalence of HBsAg according to the continents where the subjects were born. Thus, those originating from sub-Saharan Africa recorded the highest prevalence (5.25\%), as compared to subjects from the Indian Subcontinent (2.68\%) and North Africa (0.24\%). 
Specific risk factors such as nosocomial exposure, certain rituals (scarification, tattoos...), sex with multiple sexual partners and the socio-economic class were discussed in the study. All things being equal, the persistence of a high prevalence among subjects from subSaharan Africa, compared to other groups, shows that the neo- and perinatal infection is very high in the sub-Saharan Africa region [15-18]. This neo- and perinatal infection is emphasized in the study carried out by Bigot $e t$ $a l$. in Benin [11], in which eight children from $40 \mathrm{HBV}$ seropositive mothers (20\%) tested positive for HBsAg, and in the study carried out by Lohouès-Kouacou et al. in Côte d'Ivoire [19], where the incidence of perinatal transmission was estimated at $32.8 \%$.

One of the most important observations in our study was the fact that all workers admitted that they were heterosexual. The fact that subjects do not admit to risky sexual behavior, if any, is well-documented [20,21].

In Sub-Saharan Africa, the prevalence is generally high. Senegal (17\%) [22], Ivory Coast (18.2\%) [15], Madagascar (23\%) [18] and Mali (24.9\%) [5] are countries with a high level of HBV infection prevalence. Cameroon's prevalence rate is similar to that of countries such as Benin (8.26\%) [11] and the Democratic Republic of Congo (DRC) (9.2\%) [9]. Reunion has a low prevalence rate of $0.7 \%$, which is close to that of Metropolitan France, probably due to a better economy and better health conditions $[12,13]$.

Men were three times more likely to be HBsAg carriers than women. This result tallies with that of other studies conducted in Cameroon [7,8] and in the literature $[2,9,13,15]$.

The majority of workers with HBsAg were in the 20 29 years age group. This age-related result is identical to the previous study by Koanga Mogtomo et al. conducted in our country [7]. Conversely, in mainland France [13], as well as in DRC [9] and among United States immigrants [23], the 30 - 39 year age group that is that most affected. The difference with the study conducted in the DRC is at the level of the selection of the sample. The difference with that carried out in mainland France is explained by the means of contamination.

The relationship between HBsAg prevalence and low socio-economic levels has been treated by other authors [11,13-15]. Our results did not tally with theirs. This is probably due to the social ascension of individuals from underprivileged backgrounds and the fact that senior staff had several sex partners.

The difference in the prevalence rate between Douala $(12.2 \%)$ and Yaounde (6\%) supports the idea that there is a huge difference in infection patterns according to region, according to socio-economic status, and according to hygiene, in the same city. This result is similar to that obtained in the study by Mbendi Nlombi et al. in eastern
Kinshasa in DRC [9].

\section{CONCLUSION}

Our study shows a significant HBsAg carrier prevalence in a population of workers close to the general population in Cameroon, particularly among young people under 30 years, in men and in Douala. It is not different from that of the population of blood donors, which tends to confirm the hypothesis of the existence of neo-Perinatal infection in our country. This result clearly highghts the importance of strategies for vaccinating newborns and those for the treatment of pregnant women who are chronic carriers of HBsAg in controlling the risks of HBV contamination.

\section{ACKNOWLEDGEMENTS}

Hoffmann-La Roche Ltd. Cameroon Branch. Avenue De Gaulle, Rue Noury. P.O. Box 871 Douala-Bonapriso, Cameroon.

\section{REFERENCES}

[1] Liang, T.J. (2009) Hepatitis B: The virus and disease. Hepatology, 49, S13-S21. http://dx.doi.org/10.1002/hep.22881

[2] Lin, S.Y., Chang, E.T. and So, S.K. (2007) Why we should routinely screen Asian American adults for heaptitis B: A cross-sectional study of Asians in California. Hepatology, 46, 1034-1040. http://dx.doi.org/10.1002/hep.21784

[3] (2012) Hepatitis B vaccine. www.who.int/vaccines/en/hepatitisb.shtml

[4] Sharma, S.K., Saini, N. and Chwla, Y. (2005) Hepatitis B virus: Inactive carriers. Virology Journal, $2,82$. http://www.virologyj.com/content/2/1/82

[5] Dény, P. and Zoulim, F. (2010) Hepatitis B virus: From diagnosis to treatment. Pathologie Biologie, 58, 245-253. http://dx.doi.org/10.1016/j.patbio.2010.05.002

[6] Nwokediuko, S.C. (2011) Chronic hepatitis B: Management challenges in resource-poor countries. Hepatitis Monthly, 11, 786-793.

[7] Koanga Mogtomo, M.L., Louandji Fomekong, S., Fotso Kuate, H. and Ngono Ngane, A. (2009) Detection of infectious agents in blood banks in Douala (1995-2004). Cahiers d'Etudes et de Recherches Francophones/Santé, 19, 3-8.

[8] Zekeng, L. and Kaptue, L. (1990) HIV 1 serology and HBsAg and HBeAg carrier status in blood donors at the Yaounde University Hospital, Cameroon. Annales de la Société Belge de Médecine Tropicale, 70, 49-53.

[9] Mbendi Nlombi, C., Longo-Mbenza, B. Mbendi Nsukimi, S., et al. (2001) HIV and HBsAg prevalence in blood donors. Residual contamination risk in blood recipients in east Kinshasa, Democratic Republic of Congo. Médecine Tropicale, 61, 139-142.

[10] National Institute of Statistics of Cameroon (2010) The 
state and structure of the population: Demographic indicators. Imprimerie Nationale, Yaoundé, 6.

[11] Bigot, K.A., Kodjoh, N., Zohoun, I.S., et al. (1992) HBsAg seroprevalence in pregnant women and their children. Médecine d' Afrique Noire, 39, 487-490.

[12] Migliani, R., Rousset, D., Rakoto Andrianarivelo, M., et al. (2000) Infection with hepatitis B: A public health problem in madagascar. Archives de l'Institut Pasteur de Madagascar, 66, 50-54.

[13] (2005) Estimated prevalence of anti-HCV antibodies and hepatitis B markers in the general social insurance system of France, 2003-2004. Analyse Descriptive, InVS, Janvier 2005.

http://www.invs.sante.fr/presse/2005/communiques/infect ions_vhb_vhc_140205/

[14] Sidibé, S., Youssoufi Sacko, B. and Traore I. (2001) Prevalence of serological markers of hepatitis B in pregnant women in the district of Bamako, Mali. Bulletin de la Société de Pathologie Exotique, 84, 339-341.

[15] Dao, S., Bougoudogo, F., Traore, S., et al. (2009) HBsAg carrier status in Mali: Results of ten years of testing at the National Institute of Public Health Research (INRSP). Journal Africain du Cancer, 1, 68-71. http://dx.doi.org/10.1007/s12558-009-0012-5

[16] Ashraf, H., Alam, N.H., Rothermundt, C., et al. (2010) Prevalence and risk factors of hepatitis $\mathrm{B}$ and $\mathrm{C}$ virus infections in an impoverished urban community in Dhaka, Bangladesh. BMC Infectious Diseases, 10, 208. http://www.biomedcentral.com/1471-2334/10/208

[17] Lavanchy, D. (2004) Hepatitis B virus epidemiology, disease burden, treatment, and current and emerging pre- vention and control measures. Journal of Viral Hepatitis, 11, 97-107.

http://dx.doi.org/10.1046/j.1365-2893.2003.00487.x

[18] Michaults, A., Faulques, B., Sevadjan, B., et al. (2000) Hepatitis A, B, C markers prevalence in the Reunon (South Hospital and Saint Pierre Prison). Bulletin de la Société de Pathologie Exotique, 93, 34-40.

[19] Lohouès-Kouacou, M.J., Managbé Toure Hillah, J., et al. (1998) Mother-to-child transmission of hepatitis B virus in côte d'Ivoire. Advocacy for mass vaccination. Cahiers d'Etudes et de Recherches Francophones/Santé, 8, 401404.

[20] Gaillard, A., Tirtaine, C., Ouzan, D. and Follana, R. (1990). Medical care focused on the discovery of viral hepatitis markers help to reveal risk behaviors for HIV infection in blood donors. Revue Française de Transfusion et d'Hémobiologie, 33, 249-258.

[21] Ouzan, D., Pesle, B., Baldini, E., et al. (2000) Epidemiological information gotten from the progress of screening of hepatitis c antibodies from 1992 to 1996 among blood donors and autologous blood transfusion candidates in the Alpes-Maritimes Department. Gastroentérologie Clinique et Biologique, 24, 337-341.

[22] Ndongo, S., Pouye, A., Dia, D., et al. (2011) HBsAg Seroprevalence in rheumatoid arthritis in Senegal. Médecine Tropicale, 71, 632-633.

[23] Sheikh, M.Y., Mouanoutoua, M., Walvick, M.D., et al. (2011) Prevalence of hepatitis B virus (HBV) infection among Hmong immigrants in the San Joaquin Valley. Journal of Community Health, 36, 42-46. http://dx.doi.org/10.1007/s10900-010-9283-0 